HStud 26 (2012)1, 141-161

DOI: 10.1556/HStud.26.2012.1.11

\title{
A CONVERSATION BETWEEN ZOLTÁN KOCSIS AND MIHÁLY SZEGEDY-MASZÁK ON THE OEUVRE OF FERENC LISZT
}

\begin{abstract}
In a conversation held on the occasion of the Liszt year in Hungary, pianist, conductor, and composer Zoltán Kocsis and literary and cultural historian Mihály Szegedy-Maszák speak about the work of Liszt, the wide variety of influences in his admittedly uneven oeuvre, and the broad range of influences he had on later composers, such as Gustav Mahler or Richard Strauss. They also converse about the importance of creativity and even improvisation in performances of canonized compositions, and discuss the limits of the musical score as a means of conveying the intentions of a composer. The conversation touches on the performances of Liszt's pupils, including for instance conductor Felix Weingartner and pianist Emil von Sauer, who offered a dazzling rendition of Liszt's Ricordanza Etude at the age of 79. Sauer's performances of Liszt's piano concerti (conducted by Weingartner) offer clear instances of the ways in which the performer can vary the tempo of a composition, even when there are no such indications of tempo changes in the score. Kocsis comments on the contributions of pianists György Cziffra and Alfred Brendel as two of the most significant interpreters of Liszt's work. Kocsis and Szegedy-Maszák pose challenging questions regarding the notion of the completed composition and the completed work of art, as well as the authenticity of manuscript scores and the creative responsibilities of contemporary performers in the recreation and reanimation of a composer's work.
\end{abstract}

Keywords: Ferenc Liszt, Zoltán Kocsis, canon, authenticity, improvisation, Wagner, music history

M. Sz-M. - In my view there is a significant difference between the young and the old Liszt, which of course is a sort of bias on my part, as I am unable to play the Mazeppa etude, while I can play Nuage gris. Is there continuity between the two, and if so, how is this palpable?

Z. K. - The first thing that comes to my mind is that the estrangement of the Schumann-Mendelssohn School from Liszt is often explained by the latter's autotelic virtuosity. Well now, I can't condemn autotelic virtuosity en bloc, because there is something worthy of respect in it - how can I phrase this so 
that it's precise - it is the ultimate development and perfection of an act. I can imagine that the young Liszt was so taken by Paganini - and not necessarily his perfection, because perfection was undoubtedly not his primary characteristic, but for example the runs, phrases, scales on the violin, which until then had been thought of as impossible (as to what technique he used, what tunings, etc., that's a different question) - that in his own way he transformed this on the piano - as the piano of course offers more possibilities than the violin - and the results were much more spectacular, or rather more bewildering, incredible, than in the case of Paganini. And yes, I can imagine that he did this in a somewhat autotelic manner. People noted that while doing technical exercises he studied languages and read works of fiction from the music-case - as of course when doing technical exercises one doesn't necessarily have to look. However, I think he could have played even the most vapid bravura piece as a poet. In my view the most fantastic thing about Liszt was that he could dish up even bad music as something enjoyable. And I think that possibly this was the main reason for his success. Of course it is also a fact that for this reason for a very long time he did not come forward with music of his own that could be labeled as significant or epoch-making, focusing instead on transcriptions. But there were other reasons for this. Chopin was always nearby, a man who was such a par excellence composer for the piano, who could be imitated and interpreted in many ways, but never simply bypassed. Without a doubt it took some time for Liszt to swallow Chopin. I contend that Berlioz, with his own roughness or ugliness - but I don't want to insult Berlioz either, because I am very fond of his music, contrary to Chopin, who did not care for...

M. Sz-M. - Berlioz couldn't play the piano.

Z. K. - No he couldn't. But I think he had a much greater effect in the creative sense on Liszt than Chopin ever did, at the same time Chopin's perfection, let's be honest, is frightening. In and of itself the fact that....

M. Sz-M. - Although he could not orchestrate, the orchestral parts of his piano concertos...

Z. K. - No, he couldn't, but he didn't want to anyway, he wanted to compose for the piano. So the fact in itself that for example Liszt wrote his first mazurka in 1853, when Chopin had been dead for four years, and that he started writing polonaises around this time as well could be an expression not simply of his respect for Chopin, but also fear of his judgement. He may have felt liberated from some kind of pressure when Chopin died. In a manner somewhat similar to Haydn, who suddenly started composing masterpieces after Mozart's death in 1791.

M. Sz-M. - Well, he wrote some earlier than that as well. 
Z. K. - True, but what occurred after 1791 in Haydn's art - I'm thinking primarily of the incorporation of the Mozartian tone - was abrupt. Similarly, after Chopin died, Liszt began composing numerous pieces containing ideas of his own. So what you mentioned at the beginning of our conversation basically represents in reality the beginning and the end point. There is always a huge difference between the two. If we examine the artistic development of any composer in a chronological manner, however, these differences are never that glaring. This happens to be my hobby-horse: Bartók's Mandarin, for example, would be captivating for a broad audience if we began with an introduction of piano pieces from his youth, then continued with the First Violin Concerto, slowly arriving at Bluebeard's Castle, and then The Wooden Prince and the suite composed for the piano, finally works in which he consciously tackles and decidedly attempts to process the influence of Schönberg and the New Vienna School, and then we are at the Etudes written for the piano and Mandarin. And if we move through these pieces the world of Mandarin will no longer appear as foreign as it does when it seems to have just come crashing down on us without preliminary study.

M. Sz-M. - We will touch on Bartók later.

Z. K. - In the case of Liszt I think that were I to word it in a very vulgar manner I would say that he began as a French composer and later switched to being more German....

M. Sz-M. - Essentially in Weimar.

Z. K. - Yes, he turned into a German composer, and then he slowly became Hungarian, cosmopolitan, and Futurist.

M. Sz-M. - Clearly an artist is judged on the basis of his best works.

Z. K. - Of course, of course.

M. Sz-M. - But he nevertheless has low points.

Z. K. - Indeed, there are embarrassing low points.

M. Sz-M. - You yourself alluded to them. There is the Festvorspiel I think from 1856, and the Dante Symphony, also from 1856. The difference is great.

Z. K. - Maybe Liszt made the mistake - of course I will readily assert in advance that I don't know if this was a mistake, because one has to experiment a great deal in order to produce something good, think of the potter who molds and models the form only to destroy the entire thing and begin making something entirely new - that he did not destroy his immature pieces, his experimental attempts.

M. Sz-M. - He composed a fearful quanity of music.

Z. K. - And he was not only open to any and every musical impulse, but also immediately expanded on them. As a result he wandered into dead ends where he never would have ended up had he worked according to a concept, in a cer- 
tain direction. For example, based on The Legend of Saint Elisabeth and Christ I contend that he could have created the German national opera, like Wagner, but it so happened that Wagner was much better suited to the task. Because Liszt's world was much broader and more heterogeneous. Wagner essentially came to a standstill at a certain style, a certain...

M. Sz-M. - Well, but Parsifal is not bad.

Z. K. - That's not the point, and from a certain perspective Wagner is a Futurist as well, but he never went as far as Liszt. For example, with the exception of the dragon scene, Siegfried's dragon scene, I never felt that Wagner wanted to write something truly grotesque, while in the case of Liszt, this tendency is very much there, and this anticipates Bartók, because the opposites, which Liszt uses so brilliantly, will become models in the case of Bartók, at least in the early works. Liszt was able to write two types of music on the basis of the same material, later only Bartók could do the same with such genius. I think that had Liszt done what others did, such as Brahms for example, who destroyed a large amount of material - including the majority of his correspondence with Clara Schumann, which apparently he burned on the banks of a creek - then Liszt would be placed on a much higher pedestal in general opinion. True, his oeuvre would be much less interesting, because I admit, it is specifically these attempts that are the most interesting to me, and not necessarily the compositions that he later presented as finished works of art. For example there is a very early version of the Rhapsody No. 6, it wasn't even published as a Hungarian rhapsody, but as a Hungarian song, and for me it is incomparably more interesting than the final version. In fact, I would venture to argue that in the case of Liszt there is no such thing as an early or final version, only variants.

M. Sz-M. - Indeed I will ask you about this later. You mentioned Wagner. Unfortunately one can hardly avoid drawing a comparison, as little as I may like it myself. Even Alan Walker admits in the last part of his three-volume biography on Liszt that Liszt enthusiasts occasionally exaggerate the injustices Wagner allegedly committed against him. I will admit, as I am not a musician, this question does not concern me too much, but I would like to ask you: to what extent does a performer need to take into consideration the personality of a composer? When Cosima read her parents' letters, she came to the conclusion that she had neither a mother nor a father. It is hard to deny that there was a time when Liszt barely saw his children.

Z. K. - It's a fact that a woman like Countess d'Agoult, at least from the perspective of the image of motherhood at the time, could not be regarded as a mother, not to mention that the relationship was not legalized. And one cannot expect an artist on tour to be a father. 
M. Sz-M. - True, true, I withdraw the question. It is common knowledge that with respect to harmony Liszt was very innovative, but is it not possible that in certain of his works Wagner has more polyphony?

Z. K. - Yes, Bartók also emphasizes that polyphony was one of Liszt's serious weaknesses. It is very interesting that the early Bartók pieces, such as the opus 1 Rhapsody, which is acknowledged to be an afterthought of Liszt's rhapsodies, contain so many more polyphonic elements than the works of Liszt. It is also true that in certain pieces a striving for polyphony is distinctly perceptible, and not necessarily in the latest compositions. In the case of Christ or The Legend of Saint Elisabeth I sense that he is doing polyphonic exercises.

M. Sz-M. - Yes, undoubtedly. Let's return to the question of variations. Nowadays it has become almost an obsession of mine that there are no completed works of art. In the case of Liszt, there are innumerable variations.

Z. K. - I heard this phrase from Kurtág for the first time: nothing is ever completed. And if I reflect on this, it comes to signify for me that for example Schubert's Trout Quintet is not just the written score or the music I recall with my inner ear, but all the performances that have taken place since the inception of the work, including practices and rehearsals. Everything that occurs during the afterlife of the work transforms the work.

M. Sz-M. - In some of the later editions of Liszt's works only the variants believed to be completed are published. Is that right?

Z. K. - In the supplementary volumes - with which the youngest generation of music scholars has come forward and which reflect the most up-to-date research - a great deal of emphasis is placed on publishing the various versions, and not just as an appendix, but in the main part of the publication. I would have suggested at the outset - but how long ago was that - that it should be done like the publication of the complete works of Schönberg, in other words there should be a main part and an appendix. If necessary in a given case, the length of the appendix can be ten times that of the main part. However, I became unsure of this approach precisely because in the case of Liszt it is very rare that we have a version with the author's seal, something suggesting that he felt he had completed it and did not plan to continue work on it. But this is not unusual in the case of other composers either. Up to the end of his life Beethoven worked on his pieces, retouching his symphonies, adding metronomic notes. In some cases he altered phrases or the introductions of themes, if not the entire themes themselves. This is even true in the case of a composer like Bach, who is so universal and who composed mostly in his head. So I can only reiterate that in the case of such a musically malleable phenomenon as Liszt, we can only speak of variations, not to mention the by no means negli- 
gible fact that his performances must have varied greatly. There must have been so many improvisational elements, solutions conceived in the moment, conscious alterations dictated by the circumstances in these performances, all this seriously throws into question the validity of scores. But not just in the case of Liszt. If we examine compositions of which we have recordings of performances by the composer, only very rarely is it the case that merely the written score is brought to life, on the contrary there are numerous variations. By the way, publications of the complete works of a composer today devote considerable attention to these performances by the composer, and for the most part include them in the main part of the publication as possible alternatives. The complete works of Debussy adopts this approach, and the complete works of Bartók, which is projected to consist of 48 volumes, will also be done along similar lines.

M. Sz-M. - I was very glad to see that both versions of the final movement of Violin Concerto No. 2 can be found on the newest CD of the New Bartók Series.

Z. K. - Well, that goes without saying. Moreover the orchestral conclusion is the original. Zoltán Székely convinced Bartók to change the ending. Generally it is this latter version that the violinists play, but the composer nevertheless believed it to be important that the orchestral version be there in the published score. I think that Bartók was also correct when he said that Liszt's orchestral achievements were not met - from a professional point of view - with serious, constructive criticism at the time. Albeit, if from no one else, he would undoubtedly have accepted suggestions from Wagner, on the one hand formal...

M. Sz-M. - He did accept suggestions from him, as he did not write a Paradiso for his Dante Symphony.

Z. K. - Yes, but I mean from a formal point of view. True, that too is a formal point of view. But for example I'm convinced that the symphonic poems would be on a much higher level, at least the majority of them...

M. Sz-M. - I wanted to ask you about them.

Z. K. - ... if Wagner had been willing at all to share his opinion. But the problem also must have been that it seems that the friendship between Liszt and Wagner was not that profound, or that a lot of things were withheld, for Wagner often told Cosima or wrote in his own journal, The Brown Book, that he didn't like something, yet he didn't reveal his views to Liszt.

M. Sz-M. - On many occasions he spoke of them to the public in a very beautiful manner.

Z. K. - That's different. But that he could not accept the Via crucis or the Weihnachtsbaum cycle, that opinion he could have shared with his father-in-law. 
M. Sz-M. - I asked about the Liszt publication because the older volume that I own includes only the so-called final version of the Eroica etude, and to be honest I prefer an earlier version. But then here is the Second Legend. In the recording by Friedheim - who was Liszt's student - the ending is different than in the tenth volume of the complete works, which was published in 1980. This year I looked at the copy exhibited in Bayreuth in the local Liszt Museum, in which Liszt's handwritten ending can be seen, the version played by Friedheim. One should perhaps take cases like this into consideration.

Z. K. - Undoubtedly we should take them into consideration, nowadays even in the case of Beethoven's Diabelli Variations the Ries manuscript is considered a primary source.

M. Sz-M. - Let's turn to Liszt's influence. We have talked about Bartók.

Z. K. - I believe that Liszt's influence - how shall I say - is much wider than is generally believed.

M. Sz-M. - Not just Debussy, Ravel, but others, for example Richard Strauss, Busoni or Rachmaninoff?

Z. K. - Yes, that's natural, but I think we should begin with Wagner. Namely it was Wagner who in a brilliant manner took from Liszt what he required and in his case presented it in a more perfect manner.

M. Sz-M. - That is why his oeuvre is more unified.

Z. K. - Exactly. It is a fact that the kind of operatic style that one comes across in the second act of The Legend of Saint Elisabeth reached its full potential in Wagner. But it is also true that The Valkyrie's storm could not have existed without the storms in Saint Elisabeth or in Christ. If we began with Wagner, we can safely continue with Richard Strauss, because it was he who - in his own manner-perfected the style of the symphonic poems to the extent that in a given case (Don Juan) he wasn't reluctant to say even to Cosima that in his view the "old man" had wanted to write something along the lines of this work. But a direct influence can also be demonstrated in the tonal system, in harmonies. Then, so that we don't make too great a jump in time, there is Mahler. Nowadays no one speaks of the Mahler-Liszt relationship. Maybe it's unseemly? I think it is important to mention it because lately Mahler's music has enjoyed such popularity that it basically eclipses the roots from which Mahler drew nourishment, in which his conducting operas played a large role, as well as the influence that Liszt had on him. If we observe the fantastic similarities between Ce qu'on entend sur la montagne and Mahler's Symphony VIII - the echoes of Liszt's symphonic poem are most audible here - then we understand that in this case a less successful work of Liszt had an enormous impact on the formation of Mahler's style.

M. Sz-M. - If I recall it correctly, you conducted the work at the opening concert of the Liszt Year. 
Z. K. - Yes. Now, if we make a bigger jump, we arrive at Saint-Saëns, who in addition was a student of Liszt and who openly expanded on Liszt's piano technique, compositional manner, harmonics, and forms. Not to mention that Saint-Saëns must have been at least as much of a virtuoso pianist as Liszt. Not just Welte-Mignon rolls, but actual sound recordings exist. They reveal a virtuosity that is astonishing. For example the cadenza of the piano concerto entitled Africa lifts a little bit of the veil that surrounds Liszt. One can get a sense of what was behind it, who this person named Liszt was, this person whose pianistry led Wagner to say of one of Liszt's Beethoven performances that it wasn't piano playing anymore, but conjuring the dead.

M. Sz-M. - Possibly the early Schönberg? Verklärte Nacht, First String Quartet, Pelléas et Mélisande?

Z. K. - I was just about to say. The direct descendant of the Mahler-Richard Strauss line would be Schönberg, and not necessarily Verklärte Nacht, although I see some influence of Liszt in that as well. But if we consider for example Schönberg's scholarly works, it becomes clear from them that Liszt was important and essential as a composer.

M. Sz-M. - He has an interesting essay on Liszt dated 1911 which is not positive in every respect.

Z. K. - Yes, but Bartók also criticized Liszt.

M. Sz-M. - At roughly the same time.

Z. K. - Later as well, but actually, Liszt can take these criticisms. In other words, they do not diminish his value. But I must mention that I sense the influence of Liszt in the Gurre-Lieder as well. In fact it is interesting that the operetta-type sound that is present in more than one song of the Gurre-Lieder, that too can be derived from Liszt. But to take another great leap, there is the Russian school. I don't necessarily want to bring up Balakirev and the others right now, who are naturally heirs of Liszt, but there is Rachmaninoff, who did not know him personally, even though Siloti connects them.

M. Sz-M. - He studied with Liszt, correct?

Z. K. - Siloti studied with Liszt, yes, and he was Rachmaninoff's uncle. For example, in Rachmaninoff I sense that he adopted a certain Lisztian style and developed it in a much more sensitive manner than he did with Chopin. I would label Scriabin much more the heir of Chopin's music. That too of course is a dead end, because it cannot be continued, but Rachmaninoff followed much more the school of Liszt. If we look at Liszt's $F$ sharp major Impromptu, for example, and compare it with any Rachmaninoff composition of the same genre, then the similarity is beyond question...

M. Sz-M. - That is entirely convincing. 
Z. K. - ...in fact the thread of harmonies, the formal solutions, the placement of cadenzas at certain points of culmination, all typical of both composers, this is striking. And, like it or not, the great Tchaikovsky also shows signs of the influence of Liszt, whatever nonsense he may have said about him. Fragments of Onegin, the beginning of the Piano Concerto in B flat minor definitely suggest this conclusion. But one should also consider the French composers who profited from Liszt. We've talked about Saint-Saëns...

M. Sz-M. - He met with Debussy.

Z. K. - Debussy, whom he met in Rome, he remembered the encounter for life. The most important part isn't even that he heard Liszt play the piano - and whether deliberately or not this was incorporated into his piano playing and the style of his later piano pieces - but if we compare certain fragments, for example if we compare the scene in which they ascend from the castle cellar in the third act of Pelléas with Saint Francis of Assisi Preaching to the Birds...

M. Sz-M. - You mean when Pelléas and Golaud come up.

Z. K. $-\ldots$ the gradation before that part, the similarities are striking. In fact: it is really almost immaterial whether this afterthought was deliberate or not.

M. Sz-M. - And this is almost more important than the proverbial Reflets dans l'eau - Fountain of Villa d'Este parallel.

Z. K. - Exactly. But there are still many composers we have not touched upon. First I would like to mention Smetana, who openly imitated the style of Liszt's symphonic poems. But through Smetana we should also mention Dvořák, who, although he remained a friend of Brahms until Brahms' death, subsequently turned to the style of Liszt's symphonic poems, attested by his later symphonic poems, such as The Wild Dove, The Noon Witch, The Golden Spinning Wheel, and The Water Goblin.

M. Sz-M. - These compositions could be performed more often in Hungary!

Z. K. - Well, I think that I might have done The Wild Dove and The Water Gob$\operatorname{lin} \ldots$

M. Sz-M. - I even hear a bit of Liszt in the Concord Sonata of Ives, but that might be bias on my part.

Z. K. - It's possible.

M. Sz-M. - But it is not performed in Hungary. Ives in general is rarely performed, though the Concord Sonata is a significant piece of work.

Z. K. - The National Philharmonic played two important works of his in the past few years, but I will concede, more of his work should be performed. But returning to Liszt, traces of his influence can be heard in works by composers who were active much later as well, for instance, I can detect it in Edgard 
Varèse. But let's continue. As a matter of fact, other composers also could not ignore this symphonic poem style, this kind of descriptive music. I'm thinking of composers of a lesser stature.

M. Sz-M. - Such as?

Z. K. - Cornelius...

M. Sz-M. - Whom Liszt knew personally.

Z. K. - ...or Humperdinck, etc. They all composed in the style of Liszt, not to mention the host of students, who were all - their caliber is beside the point composers themselves. The influence of his style is felt later, much later: we have mentioned Bartók, but in certain ways in Enescu, in Kodály, in Dohnányi. Therefore we are right to think that the influence of Liszt was wide, both in terms of time and in terms of space. Music would undoubtedly be different had it not for him.

M. Sz-M. - As a pianist he strove to achieve an orchestral sound. Can one speak a bit more on this subject?

Z. K. - Well of course, and this can be considered from several perspectives, although it belongs somewhat to the area of musicology. It's a fact that I was in similar shoes very early on as a small child. When one attempts to achieve an orchestral effect on the piano, when one tries to imitate the effect of an orchestra, one lays one's finger on the keys in an entirely different manner. Not only the keys, but the use of the pedals is also different, in fact the entire physiology of the playing changes in a certain respect. In other words I think that when Liszt wrote down his transcriptions, which by many were regarded as impossible to play or as impossible to bring to life, he only wrote down what could be written down.

M. Sz-M. - How should the compositions of Liszt be played anyway? A student was playing one of his rhapsodies. Why don't you play it like this - asked Liszt, then sat down and proceeded to play on a second piano the fragment in question in a much freer manner. - That's not how it is in my copy - the youth said defiantly. - Oh, it shouldn't be understood strictly - answered Liszt.

Z. K. - It absolutely needn't be understood literally. And I believe nothing should.

M. Sz-M. - Well, the opera fantasies should certainly not be taken literally. In 1886 Liszt commented that he always played these pieces freely, not the way they appeared in print.

Z. K. - But there are simpler examples. The same text, we are given the same text. You will undoubtedly read it aloud differently than I. But not because our voices differ, but because of our individual interpretations, the manner of binding sentences together, for one of us one word will be important, and another for the other person. I believe that even if we automatize the majority of the main aspects, there remains plenty of room for improvisation in the case 
of a truly talented person. As for someone who is not talented, he or she should probably not be engaged with performing art on a professional level. I say this only in parentheses.

M. Sz-M. - This is entirely so.

Z. K. - In any case I think that it was again Bartók who hit the nail on the head, and perhaps exactly with regards to Liszt, when he claimed that our method of musical notation is inadequate. It does not record precisely the intention of the composer. Indeed this is the case. How can a Bartók agogica be written down precisely? Or how could one reproduce the manner in which Gershwin played his own pieces on the piano? How could this be done using the current musical notation? It can't! Or how can we write down how a folk singer sings? The best manner of notation is possibly that of László Lajtha. Perhaps it was he who was able to do this best. But even that does not render the manner in which a folk singer sings a $100 \%$.

M. Sz-M. - You mentioned markings with respect to the use of pedal.

Z. K. - Yes.

M. Sz-M. - In some places there are many, in other places there are hardly any. Z. K. - Yes.

M. Sz-M. - One could take the ninth piece in the series entitled Harmonies poétiques et religieuses. There are altogether two marks concerning pedal use. Does this mean that one can only use the pedal in these two places?

Z. K. - No, of course not. It is a different matter that I would not insist on the use of pedals in the first half of the piece. No doubt you remember how Sviatoslav Richter played it at the Vigadó (the piece in question is the Andante lagrimoso). He did not force it, but at the same time there are surprising things. The Dance in the Village Inn, which we of course know as the First Mephisto Waltz, begins with pedal. No one plays it with pedal, because no one takes the effort to listen to the orchestral version, maybe because otherwise it would become immediately apparent what Liszt really intended. And here, in connection with the pedal, we return to what you mentioned earlier, namely where piano playing ends and the orchestral illusion begins. With regards to this I believe that the piano doesn't end and the orchestral illusion doesn't begin, but rather the two are one and the same. There are numerous works for piano - and in the case of Liszt in particular many of these pieces emerged from the studio - which could easily have been symphonic poems. I am thinking about Vallée d'Obermann, for example, but we could add to this list Bénédiction or even the Dante Sonata. I think that because he was always relying on his inner hearing, he created compositions for the piano that someone who was "only a pianist" would undoubtedly not have been capable of creating. It is another matter that this was also a disadvantage for him, be- 
cause when he had to orchestrate a piece, he set out from his achievements at the piano, assuming that in the future similarly brilliant musicians would revive his orchestral works. Unfortunately this was not so, and that's the reason why for example when passages for the piano appear in his orchestral pieces and the orchestra does not play them with sufficient force, they fail to make a great impression, or at least one is left with a sense of something lacking. Well, it is this sense of something lacking that Wagner filled brilliantly in his own compositions, of which one really cannot say that they are piano-like. Why? Because he thought primarily in an orchestral setting. It is a wholly different matter that later Liszt himself learned to orchestrate well.

M. Sz-M. - He wasn't very good at it, but only at the beginning.

Z. K. - In his case it was also a problem that in many cases lackeys finished the work instead of him.

M. Sz-M. - Raff for example.

Z. K. - And the Doppler brothers, not to mention the anonymous heroes.

M. Sz-M. - Returning to a previous question, I wanted to ask how much rubato was necessary when performing a composition for the piano by Liszt? To what extent should the spirit of 19th century music playing be taken into consideration? Let me mention an example: during the performance of the $\mathrm{Sec}$ ond Rhapsody Alfred Cortot uses significantly more rubato than...

Z. K. - Let's just agree that Cortot used significantly more rubato than others.

M. Sz-M. - Yes, but for me, even though I must candidly say that the Second Rhapsody is not my favorite, I enjoy the way he plays it.

Z. K. - Yes, it's interesting how the performances of those whose personalities come across are the closest to us, or we remember them best. Recently I listened to a recording of György Cziffra with a very well-known pianist. All of a sudden he began criticizing it, saying that Cziffra was not sticking to the score. To this I replied - as a true music philologist would - that the whole performance was good as it was. He should not stick to the score, if it doesn't suit him, because that would make the performance worse, or at least less authentic. I think that Liszt was very right in what he said to that girl, namely that he encoded in these compositions the possibilities of various performances, or that in many cases he did not write down more than the frame of a piece. One could say these are individual versions that are unfinished in this phase, or rather they are some kind of solution that he was forced to adopt. I am thinking of the Mazurka in A major, for example, which we have also previously mentioned, here in a separate ossia line the possibility of eventual orchestral instrumentation is included! 
M. Sz-M. - Can we draw any conclusions regarding Liszt's piano playing on the basis of what we hear in recordings of his students? I'm thinking of recordings of Sauer or Lamond.

Z. K. - Earlier you mentioned Fiedheim, whose pianistry, according to ear-witnesses, was most akin to that of Liszt. And then there is Sauer, as you say.

M. Sz-M. - He played the Ricordanza etude at the age of 79. In my opinion superbly.

Z. K. - You know how much that recording is worth? It was 350 pounds twenty years ago.

M. Sz-M. - He has two piano concerto recordings. Weingartner is conducting, who also studied with Liszt.

Z. K. - It is very interesting that in those two piano concerto recordings Sauer permits himself so much freedom, such a wide range of variations in tempo, that one is truly unable to decide whether these originate with Liszt, that they were affirmed by Liszt, or not. Because in the case of artists of such stature one could not say that they slowed down because the material is difficult. Take the A major piano concerto. I remember the end, the way Sauer plays it: he slows down at a point and then again accelerates, none of which appears in the score. And as far as I'm concerned, if he can do this in an authentic manner, he should. This music can survive it. Indeed I am convinced that every style, the music of every composer has its own system of agogics. Let me give an example. If you grind out the first movement of Brahms' fourth symphony in one tempo, then either the beginning will be incomprehensible or the end will be tedious. Well, if you look at the tempo, at the stretta with which one ends the first movement compared with how one begins, the difference is more than double. Yet there is not even a hint regarding this from the author, nevertheless this difference in tempo is characteristic of most performances. And this music not only withstands this, but demands this system of agogics. I think that if this is so in the case of Brahms - which is of course strict German music - then why would it not be even freer in the case of Liszt, allowing more liberty for the performer?

M. Sz-M. - Liszt pupils also published scores. For a long time - undoubtedly the fault is mine - I didn't understand why Horowitz played the octaves at the beginning of the Sonata in B minor staccato. There are of course two recordings, and in both he begins the sonata staccato. Then someone showed me a score edited by d'Albert in which it reads: "wie pizzicato." Sauer's edition is different in many respects.

Z. K. - However Horowitz may play it, the first two octaves are marked staccatissimo. 

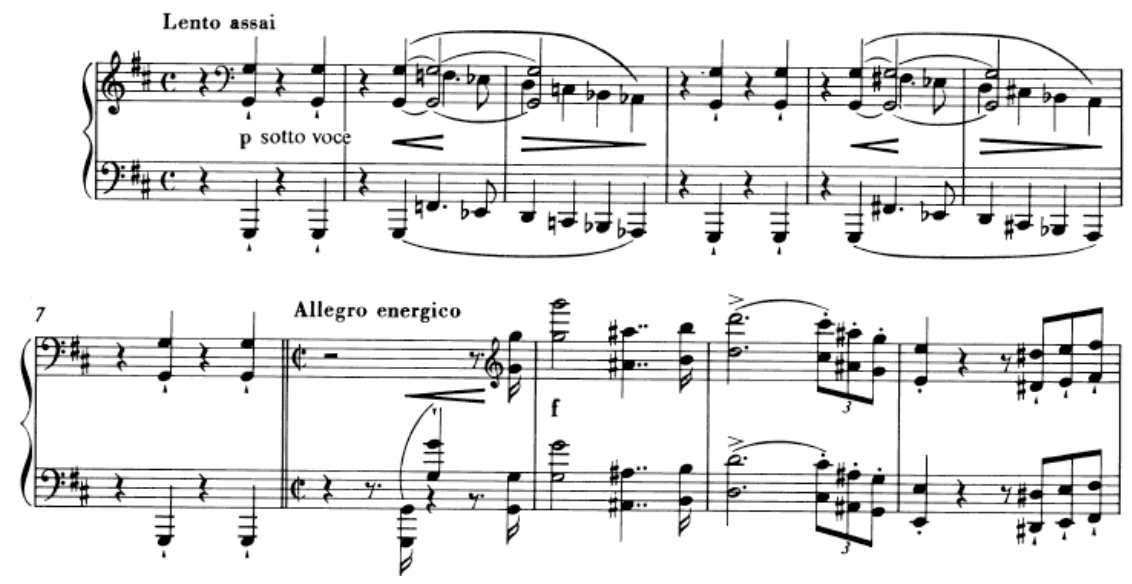

Incidentally the Les Préludes also begins with those two, repeated notes. I imagine you prefer that also to be played dry, rather than as a resonated pizzicato.

M. Sz-M. - Yes. That's right.

Z. K. - Well, the beginning of the Sonata in B minor is the same, except that there the first note is G. In fact, it appears again before the fugato that anticipates the recapitulation, there too I feel it to be a short sound, which - and this should not be neglected - is reinforced by the manuscript.

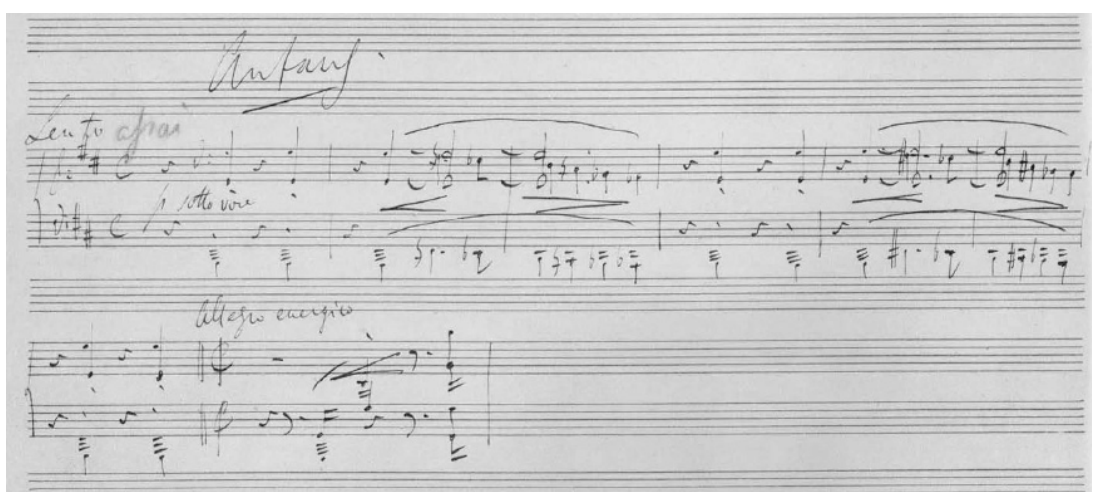

So at the beginning of the work and then before the fugato, where in the first measure the staccatissimo marks can clearly be discerned:

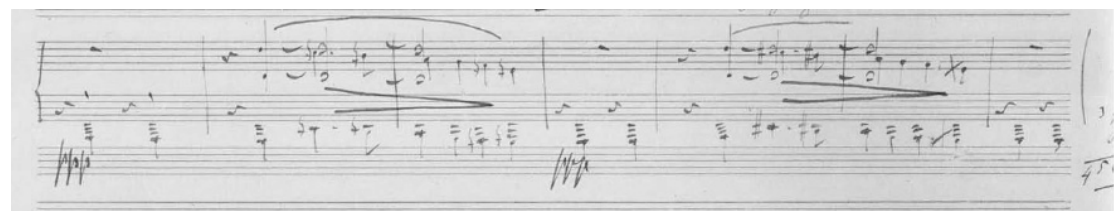


But since the sonata in B minor has come up, let's examine how this piece ends.
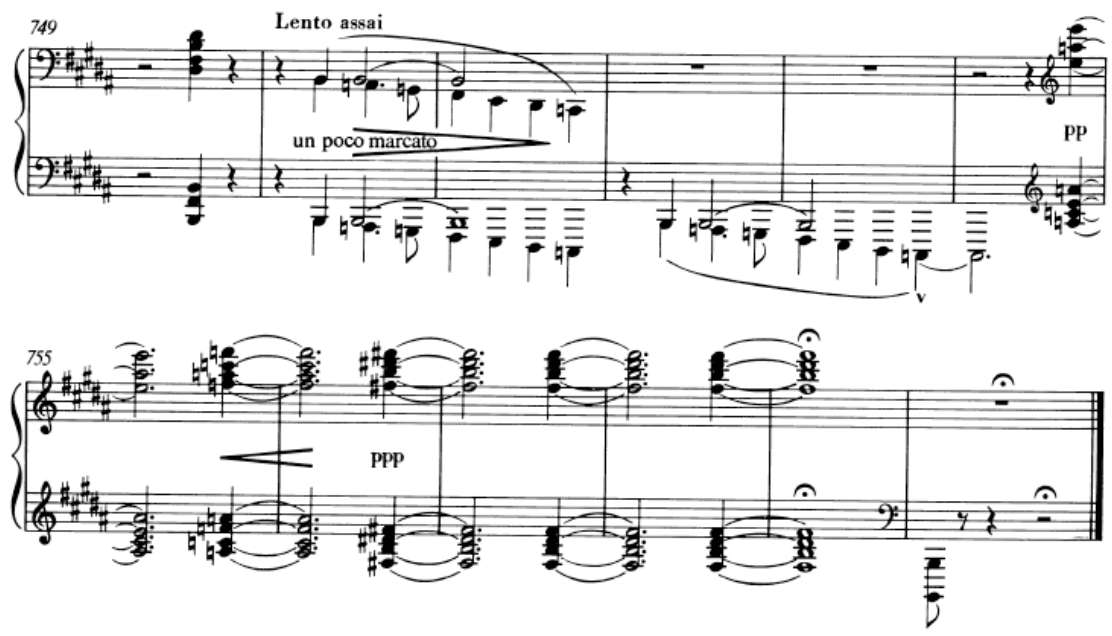

The clash of B and C, which doesn't avoid the B tritone (the F major of bar 755). Why is this so terribly important? Because Richard Strauss in 1896 wrote this in the opposite order, a confrontation of B and C, with a $\mathrm{C}$ tritone (trombones) - in the Thus Spoke Zarathusra. In the following manner:

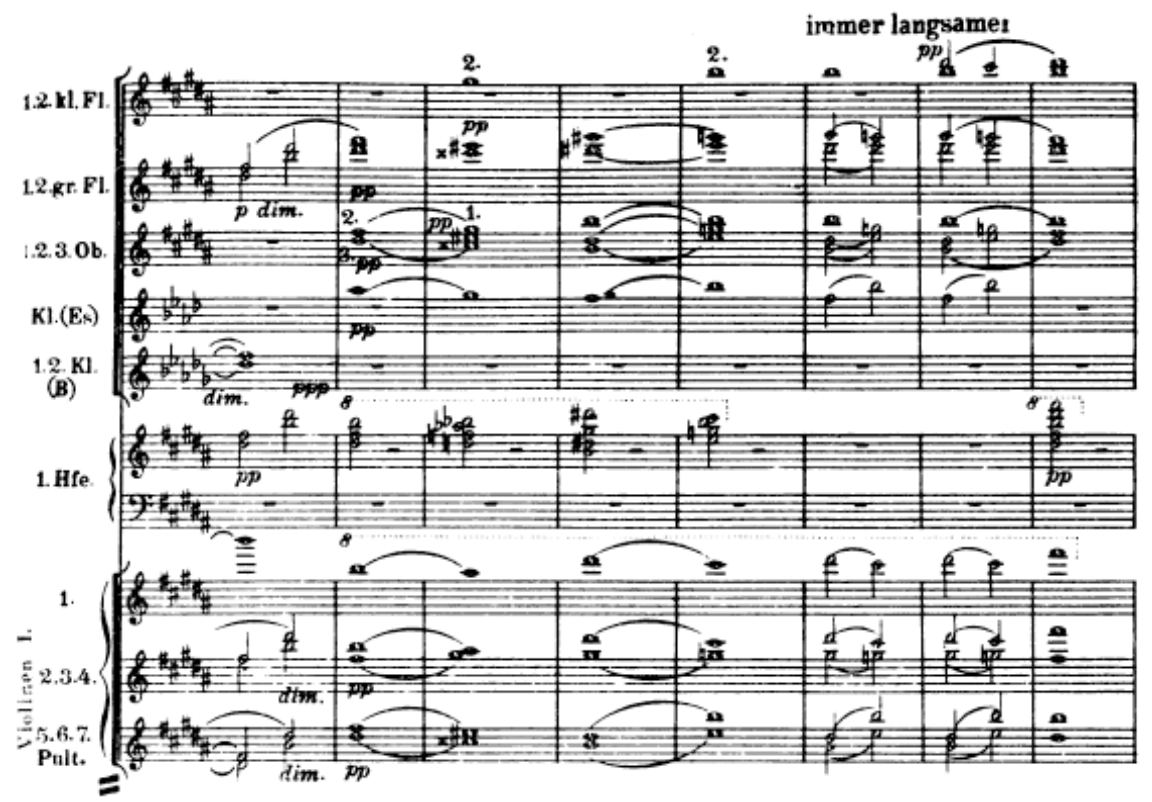




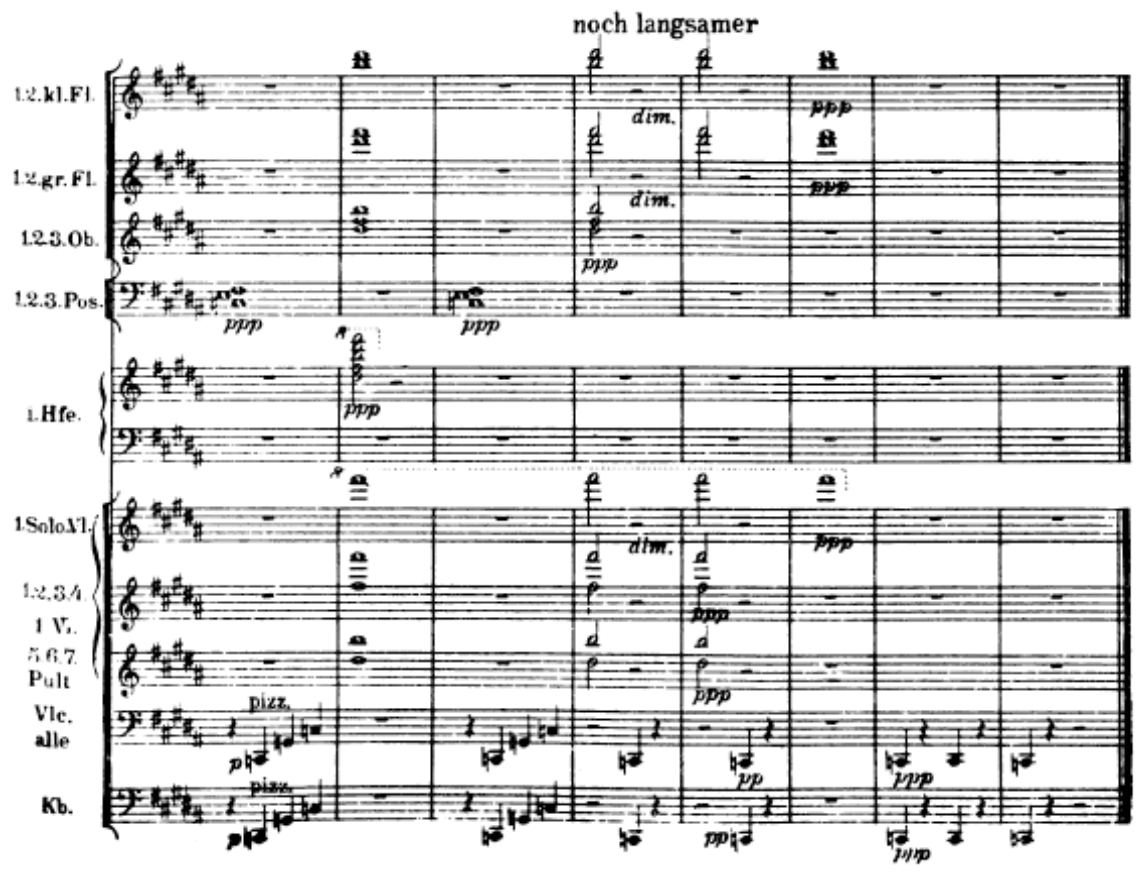

One even could say that there are more similarities than differences, as in both cases the key of elevation is B major, while earth-boundness is symbolized by $\mathrm{C}$. The major difference is the basic tonality of the pieces. This page of the Strauss score could - in my opinion - in no way have been written without former knowledge of the Sonata in B minor.

M. Sz-M. - This seems very convincing.

Z. K. - These effects are much more important than the showy formal similarities or similarities in motifs or themes. And in some wholly mystical manner these permeate the style of any composer who makes use of them.

M. Sz-M. - Is the parting of composer and performer in our time not unfortunate? Thankfully this is not true in your case.

Z. K. - Well, yes, yes, it is indeed unfortunate.

M. Sz-M. - Busoni, Rachmaninov, Dohnányi, Bartók are counterexamples. Maybe even Boulez. I would timidly mention Furtwängler. However significant or insignificant a composer may have been, he nevertheless approached their work from a composer's point of view.

Z. K. - Oh indeed! Klemperer as well. But this can be said about most significant performers of the past. Because on some level they all understood composing, they studied it. Not to mention the performers who were miniaturists, but as such were magnificent. I think of artists such as Kreisler, Hofmann, Rosenthal or even Grieg. What you mention, we could do something to ad- 
dress that. On the college level I would make composition an obligatory subject of study. As for composers, I would require them to know an instrument well enough to give several concert performances a year.

M. Sz-M. - What instruments should they have to play?

Z. K. - Well, they should definitely be able to play the piano. I know a violinist who plays the piano masterfully.

M. Sz-M. - Grumiaux was one.

Z. K. - Yes Grumiaux was one, but also Julia Fischer, for example.

M. Sz-M. - Yes, indeed.

Z. K. - She plays the piano and the violin. But there is also Barnabás Kelemen, who was perfectly able to play Bartók's Ostinato.

M. Sz-M. - What sort of instrument should a pianist use when playing Liszt? Some pianists prefer Erards.

Z. K. - I don't believe in any of this. I don't even share this Pleyel madness with regards to Chopin. All in all I believe in historicism to the point that these original instruments truly shed light on certain essential segments of the music. For example I can imagine that the viola gamba is much better able to shed light on the essence of some compositions than the cello, but I agree with Miklós Perényi, who says that yes, cellists must learn how to play as if they were playing the viola de gamba. Well, I could insist on only playing Mozart and Haydn on fortepiano from now on. But first, the fortepiano is a different instrument today, and second, I can create the sounds on a contemporary piano. This is perfectly possible, whatever people may say, though of course one needs to apply special effort in order to achieve that sound.

M. Sz-M. - Yes, that's clear.

Z. K. - Thus I wouldn't necessarily insist on playing Liszt on an Erard. Liszt was delighted when he came across a serious instrument. There are two Bechsteins in the house in Weimar.

M. Sz-M. - In later years he even had access to Steinways.

Z. K. - In Weimar he used Bechsteins, then yes, he played on Steinways, but he also is depicted next to Bösendorfers in photographs and illustrations. In other words I believe that Liszt in this regard was very open, and he composed in such a manner, structured passages for the piano so that they speak for themselves.

M. Sz-M. - Who played Liszt beautifully in your view? Candidly speaking, sometimes I was bored by Brendel's interpretation, for example his Beethoven sonatas. But I recall a very beautiful Bénédiction, indeed he also played the Two Legends in Pest.

Z. K. - Yes. He played the Bénédiction following a fairly boring Schubert sonata, and that was a cathartic experience. Incidentally - of course this has no bearing on the subject at hand - I took him out to dinner afterwards, up to the Cita- 
del, the only place where there was no music, because he detested music in restaurants, and imagine, we sit down, order our meals and then a jazz band consisting of 15 members appeared and began playing. Poor Alfred, you can imagine. But returning to our conversation, the Bénédiction was truly marvellous, but I could not agree with the contention, attributed to him, accorinding to which a single composition by Liszt is worth more than all of Chopin. But it is certain that with his intellect he came very close to the essence of Liszt's music. I don't know if you are aware of it, but he has a recording by Vox of Weihnachtsbaum from 1951.

M. Sz-M. - It is first-rate.

Z. K. - Well that for example is very good. So, there's Brendel among the, let's say intellectual types. But in other respects it is nevertheless György Cziffra's name that comes to my mind.

M. Sz-M. - Your youth is your disadvantage. I was able to hear him perform the Mazeppa Etude in Pest. It was astonishing.

Z. K. - I believe it.

M. Sz-M. - There are many composers whose works I wouldn't care to listen to in his interpretation, but not Liszt.

Z. K. - Even in his later years how he performed the second Hungarian Rhapsody! That was tempestuous. Or how he plays the sixth on film. So I think that in certain respects he cannot be surpassed, and in other respects Richter.

M. Sz-M. - Although I have a recording from Kiev of the Sonata in B minor, it wasn't exactly a success.

Z. K. - Yes, the Sonata in B minor was not his piece.

M. Sz-M. - Of course he played certain pieces magnificently.

Z. K. - The Piano Concerto in A major, the manner in which he approached the eight transcendental etudes - those he played, because he leaves four out of the series - is wholly bewildering. And that desire to discover, the craving with which he surveyed late and early work of Liszt. For example at the concert at the Vigadó mentioned earlier he not only played the Andante lagrimoso, but also the Ave Maria and the Pensées des morts written for the Lebert und Stark piano school, and those were highly moving performances

M. Sz-M. - He did recordings of these in 1984.

Z. K. - But I could name earlier recordings of his. It was essentially through him that I discovered the Scherzo and March. If I want to listen to Feux follet, Richter's name is among the first that comes to mind.

M. Sz-M. - Cziffra also performed it.

Z. K. - Yes, but with respect to Feux follets I somehow regard Richter as more virtuosic than Cziffra. He takes more risks, one could say he is less calculated. One also cannot disregard the fact that enormous strength is required in the performance of Liszt. And I would not like to say anything about women, 
because there are fantastic female performers, but the majority of female performers are closed out of the Liszt repertoire because of this.

M. Sz-M. - You have played and conducted numerous pieces by Liszt.

Z. K. - Yes.

M. Sz-M. - Do you have any plans in the future to do this? This was some time ago, and I undoubtedly missed out on a lot, because I taught most of the time in the United States, but if I recall correctly you once played Haydn and Liszt at the Music Academy.

Z. K. - I don't remember that anymore, but essentially what was important for me in Liszt, pieces in his oeuvre that I believed had been overlooked, I would take them out from time to time.

M. Sz-M. - The first symphonic poem would be an example?

Z. K. - Yes, Ce qu'on entend sur la montagne, but also the choral work entitled Die Glocken des Strassburger Munsters, and I would also include here the Psalm 13. Although I think the former is much more modern. It resembles a fragment of a Wagner opera. Psalm 13 is much more sacred.

M. Sz-M. - One doesn't hear them performed often.

Z. K. - Unfortunately no. These pieces are very important for me, but other things are important as well. The Grosses Konzert-Solo as a preface to the Sonata in $B$ minor, its early formulation, but of course it is brilliant on its own as well. The pieces in the third volume of the Années de pelerinage were revelations for me, I played all of them as well.

M. Sz-M. - That recording was reissued many times.

Z. K. - Or among the paraphrases and transcriptions there is Norma.

M. Sz-M. - I think he learned a lot from Bellini in his youth.

Z. K. - Oh yes, but not just him.

M. Sz-M. - Wagner as well.

Z. K. - And Chopin. Chopin positively adored Bellini, indeed they were on good terms.

M. Sz-M. - If we look back at the Liszt Year, because of course one cannot avoid mention of this, are you satisfied with the results?

Z. K. - To be honest I expected considerably more scholarly publications, publications that would have shed light on and broadened the established understanding of Liszt. For example, I think that a truly professional photo iconography of Liszt is much needed, just as there should be a complete publication of his correspondence. Because that would also be of literary value.

M. Sz-M. - It would not be easy to gather the letters. Even I have one in my possession. He wrote it to Miklós Barabás, my great-great grandfather.

Z. K. - A very small portion of his letters has been published, and even those only sporadically. In 1911, on the occasion of the Liszt Centenary, a publication was done by Vilmos Csapó. It was a publication of letters without any 
changes and accompanied by minimal notes. Furthermore, they were published in their original languages, in other words they didn't even bother with translations. And then János Hankiss has a two-volume collection.

M. Sz-M. - That too is fearfully old.

Z. K. - Old and also not complete. From the following period, the collection published based on László Eősze's research in Rome; and Mária P. Eckhardt's selection deserves mention, but a great deal is still missing. The same way in which Debussy's letters have been published or János Demény edited Bartók's correspondence, letters of Liszt should have been collected. Not to mention that I assume there are far fewer letters still extant than in the case of Bartók.

M. Sz-M. - Well, I too find this regrettable. And also that there is of course this CD prize and the strange privilege befell me, I suppose due to my impartiality, to be included, in fact made head of the committee. I confess it took us more time than I might have expected to make our selection. Finally the award was given to one of Haselböck's recordings, a CD on which they are playing on 19th century instruments at least.

Z. K. - Organ?

M. Sz-M. - No, symphonic poems.

Z. K. - Haselböck is first and foremost an organist.

M. Sz-M. - Yes. Previously he had recorded all of the organ works. Now he leads an ensemble that performs the symphonic poems on 19th century instruments. I have heard three of their recordings.

Z. K. - I haven't heard any.

M. Sz-M. - Your CD came out too late to be taken into consideration, because in 2011 recordings from 2010 were judged. Hopefully there will be even better recordings that we can select from in 2012. The piano recordings were less engaging than I might have hoped in 2011.

Z. K. - Well, that's interesting. There's a pianist, Leslie Howard...

M. Sz-M. - Who recorded all of the piano works. 95 disks?

Z. K. - I don't know how many disks, but recently I listened to one of the recordings and it was well, dull. In other words it was like a ...

M. Sz-M. - ... a recording of the complete works?

Z. K. - Yes, a recording of the complete works, in which there are works that are momentous for the performer and then there are the leftovers. Well, I had hoped to avoid this mistake in my recording of the complete works of Bartók, and it ended up taking ten years. And if someone really sets out to record all of Liszt and it's 95 disks, it should take 100 years. Well, I don't know. Incidentally, I think Imre Mező might have said that a recording series of the complete works of Liszt will be finished by 2080 . 
M. Sz-M. - One of the problems is that in the case of his lieder, the different variations should all be included. As there are singers, or were - as far as I know Brigitte Fassbaender is still alive, just not performing - who often did not sing the last version, but rather an earlier one, but offered a thorough explanation as to why.

Z. K. - Well, there are lots of similar cases in the music world. Boulez for example will only conduct the first variation of Petruska. Or I myself only play the 1913 version of Rachmaninoff's Sonata in B flat minor, because I regard the second version as simply inferior. So there are cases like this. With Liszt as well. There are some who prefer the Album d'un Voyageur to the Années de Pèlerinage. I can understand them.

M. Sz-M. - Thank you very much for your time.

(Translated by Zsuzsanna Szegedy-Maszák) 